\title{
Insight of in-situ porosity and compressibility of the GC 955 Gulf of Mexico hydrate reservoir
}

\author{
Yi Fang ${ }^{1, *}$, Peter B. Flemings ${ }^{1,2}$, Hugh Daigle ${ }^{3}$, Steve C. Phillips ${ }^{1}$, John T. Germaine ${ }^{4}$ \\ ${ }^{1}$ Institute for Geophysics, The University of Texas at Austin, Texas, 78712 US \\ ${ }^{2}$ Department of Geological Sciences, The University of Texas at Austin, Texas, 78712 US \\ ${ }^{3}$ Hildebrand Department of Petroleum and Geosystems Engineering, The University of Texas at Austin, Texas, 78712 US \\ ${ }^{4}$ Department of Civil and Environmental Engineering, Tufts University, MA, 02155 US
}

\begin{abstract}
We characterize the in-situ porosity and compressibility of a coarse-grained hydrate reservoir in Green Canyon Block 955 in the deepwater Gulf of Mexico by performing experiments both on a hydratebearing sandy silt pressure core and on the same reservoir material after reconstituting. Uniaxial consolidation experiments demonstrate a small difference in porosity between a reconstituted sandy silt sample $\left(S_{\mathrm{h}}=0, n=\right.$ $\sim 0.38)$ and a hydrate-bearing sandy silt $\left(S_{\mathrm{h}}=83 \%, n=0.39-0.40\right)$ at in-situ effective stress (3.8 MPa). Both measured porosities generally agree with the in-situ porosity ( $\sim 0.38$ to 0.39 ) of the reservoir formation that was best-estimated from both LWD and calibrated PCATS densities. The compression index of pressure core at $3.8 \mathrm{MPa}$ is $\sim 0.05$ to 0.1 , slightly stiffer than reconstituted sandy silts $\left(C_{\mathrm{c}}=0.11\right)$. This difference in porosity and compression behaviors between hydrate pressure cores and reconstituted material implies that (1) analysis of reconstituted sediments from hydrate-bearing pressure cores provides a simple and intuitive approach to understand some petrophysical components of the hydrate reservoir; and (2) the high-saturation hydrate in the pores of sediments makes the hydrate reservoir slightly less compressible, suggesting a non-contactcementing hydrate morphology in the pressure core.
\end{abstract}

\section{Introduction}

Methane hydrate is a crystalline solid composed of methane molecules trapped in cages of water molecules [1]. It is stable at low temperatures and high pressures, which in natural environments is commonly found in permafrost regions, outer continental margins, and shallow basin sediments $[2,3]$. Methane hydrate has been considered as a potentially vast resource of fossil fuel energy, which has a high energy density, large storage, and widespread distribution across the globe [4]. Methane hydrates also comprise a large global pool of organic carbon and may play a role in Earth's climate system [5, $6]$.

Many numerical models have been developed and deployed for predicting the dynamic behaviors of hydrate formation [7, 8] and depressurization-induced gas production $[9,10]$. To make intelligent judgments about how hydrate deposits formed and how they might be produced in an environmental and economic manner, all of these models require the best possible knowledge of the reservoir's petrophysical nature.

Hydrate reservoir porosity is one of the most significant petrophysical properties and it requires careful measurement in the laboratory. Similar to other hydrocarbon reservoirs, hydrate reservoir porosity $(n=$ $\left.V_{\mathrm{p}} / V_{\mathrm{b}}\right)$ is defined as the volume fraction of the porous medium (i.e., sandy silt in this study) that is void space.
These pores can be filled by hydrate, liquid, or gas. An accurate measurement of in-situ porosity is necessary to accurately identify the empirical correlation between relative permeability $\left(k=k_{\text {eff }} / k_{0}\right) v s$. hydrate saturation $\left(S_{\mathrm{h}}\right.$ $\left.=V_{\mathrm{h}} /\left(n \cdot V_{\mathrm{b}}\right)\right)$.

The porosity evolution of a hydrate reservoir in response to reservoir compression is crucial for evaluating the long-term flow behavior $[10,11]$, pore pressure evolution [12], and reservoir deformation [13, 14]. The porosity normally decreases due to the elevated effective stress as the depressurization method is applied in gas production of a hydrate reservoir [14]. This porosity change due to effective stress, if not considered in numerical models (i.e., the geomechanical effect is not considered), would result in an over-estimation of predicted gas production when comparing to the real world gas production operation [15].

In 2017, the University of Texas at Austin led an offshore gas hydrate drilling expedition at Green Canyon Block 955 (GC 955) in deepwater Gulf of Mexico (GOM), where two wells (Hole GC 955 H002 and Hole GC 955 H005) were targeted at hydrate-bearing sediments and were drilled to retrieve pressurized gas hydrate saturated cores [16]. This project focuses on characterizing natural methane hydrate as a future energy resource and aims at understanding the genesis of natural hydrate in the GOM. In this study, we gain insight into in-situ porosity by

\footnotetext{
* Corresponding author: yi.fang@utexas.edu
} 
measuring the retrieved hydrate-bearing pressure core under recreated in-situ conditions in the laboratory.

This paper reports on the results of the in-situ porosity and compressibility properties of pressure core (H005-4FB-8) collected in the GC 955 hydrate reservoir. First, we estimate porosity and hydrate saturation of the retrieved pressure core with Pressure Core Analysis and Transfer System (PCATS) Computed Tomography (CT) images, gamma-ray density, and quantitative degassing. Second, we compare the compression behavior of hydrate-bearing sandy silt pressure core and the reconstituted core sample with the same parent material. Finally, we discuss why an accurate estimation of in-situ porosity is a pre-requisite for an accurate estimate of hydrate saturation. We also discuss the implication of compression behaviors on hydrate morphology in our pressure core.

\section{Methods}

\subsection{Sample description and preparation}

We selected a natural hydrate-bearing pressure core (H005-4FB-8) for experimental analysis. The entire core section was first X-ray scanned; then, a small section of the core was selected (Figure 1, yellow box), cut, and transferred to permeameter by PCATS [17]. The selected pressure core section is composed of a sandy silt lithofacies with consistent gamma-ray density and P-wave velocity values (Figure 1 and Table 1), implying that the core has consistent characteristics (e.g., porosity) throughout the same lithofacies.

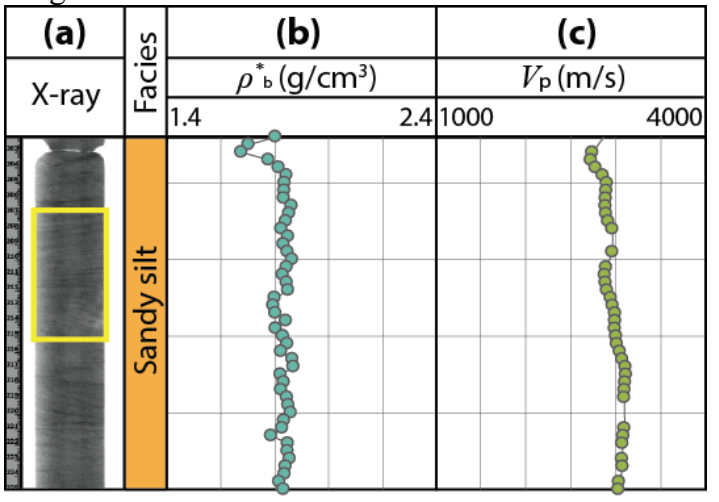

Fig. 1. (a) PCATS X-ray image of sandy silt core interval (H0054FB-8 (423.56 - $423.79 \mathrm{mbsf})$ ); the yellow box outlines the interval of the sample analyzed. (b) Gamma-ray attenuation bulk density (also known as total density) $(\rho *$ b) from PCATS taken at $0.5 \mathrm{~cm}$ intervals. (c) PCATS P-wave velocity $\left(V_{\mathrm{p}}\right)$.

Table 1. PCATS scan and the LWD inferred in-situ properties

\begin{tabular}{|c|c|}
\hline Sample Name & 4FB-8 \\
\hline Lithofacies & Sandy silt \\
\hline Sample Depth $(\mathrm{mbsf})$ & $423.61-423.69$ \\
\hline Location in Core $(\mathrm{cm})$ & $207-215$ \\
\hline PCATS P-wave Velocity, $V_{\mathrm{p}}(\mathrm{m} / \mathrm{s})$ & 2947.7 \\
\hline PCATS Bulk Density, $\rho^{*} \mathrm{~b}\left(\mathrm{~g} / \mathrm{cm}^{3}\right)$ & 1.83 \\
\hline Best-estimated Bulk Density, $\rho \mathrm{b}\left(\mathrm{g} / \mathrm{cm}^{3}\right)$ & 2.03 \\
\hline LWD Bulk Density, $\rho \mathrm{b}\left(\mathrm{g} / \mathrm{cm}^{3}\right)$ & 1.99 \\
\hline PCATS Porosity, $n(-)$ & 0.38 \\
\hline
\end{tabular}

\begin{tabular}{|c|c|}
\hline LWD Porosity, $n(-)$ & 0.38 \\
\hline Hydrate Saturation, $S_{\mathrm{h}}(-)$ & 0.83 \\
\hline
\end{tabular}

After the consolidation test of pressure core was done, the material was dissociated, disaggregated, and reconstituted with uncompaction technique [18]. This method uniformly packs the disaggregated sandy silt sediments into a fixed-diameter steel ring to achieve a homogenous material. A comparison of hydrate-bearing sandy silt and the reconstituted core is illustrated in Figure 2 , which shows abundant ripple cross-laminations in the natural core but no observable structures in the artificial core.

\section{(a) Intact 4FB-8 core sample}

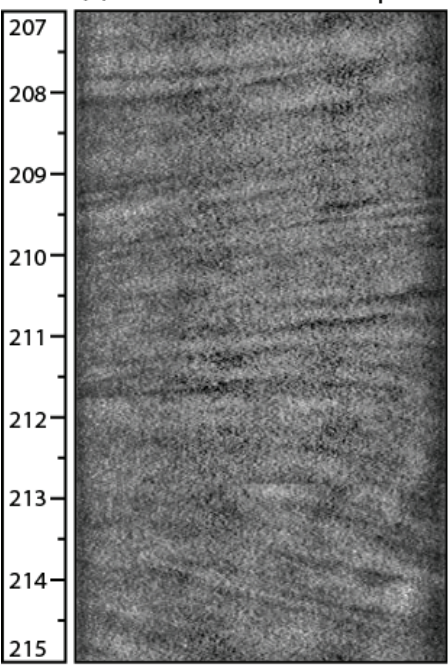

(b) Reconstituted 4FB-8 (after CRS test)

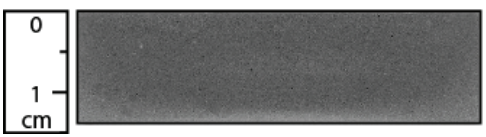

Fig.2. (a) The $8-\mathrm{cm}$ sandy silt lithofacies portion of hydratebearing core 4FB-8 labeled with the yellow box in Fig.1(a). (b) The sample reconstituted from parent sediments in (a) by undercompaction technique. The sample was prepared for the uniaxial consolidation test and it was CT-scanned postconsolidation test. The bright edge at the bottom of (b) is due to beam hardening during CT scanning [19].

\subsection{Porosity estimation}

We describe 4 approaches to estimate the porosity of hydrate-bearing pressure cores: (1) PCATS porosity $\left(n_{\text {PCATS }}\right)$; $(2)$ the logging while drilling (LWD) porosity $\left(n_{\mathrm{LWD}}\right)$; $(3)$ the moisture and density (MAD) porosity $\left(n_{\mathrm{MAD}}\right)$; (4) the mercury injection capillary pressure (MICP) porosity $\left(n_{\mathrm{Hg}}\right)$.

$n_{\text {PCATS }}$ is calculated from the bulk density $\left(\rho_{\mathrm{b}}\right)$ of the core sediments assuming only water and hydrate are present in the pores:

$$
n_{P C A T S}=\frac{\rho_{b}-\rho_{g}}{s_{w} \rho_{w}+s_{h} \rho_{h}-\rho_{g}}
$$

The grain density $\left(\rho_{\mathrm{g}}\right)$ is measured directly; the pore fluid density is assumed to equal that of seawater $\left(\rho_{\mathrm{w}}=1.035\right.$ $\left.\mathrm{g} / \mathrm{cm}^{3}\right)$ and the hydrate density $\left(\rho_{\mathrm{h}}\right)$ is assumed to equal 0.9 $\mathrm{g} / \mathrm{cm}^{3}$. 
$n_{\text {LWD }}$ is also calculated with Eq. 1; however, the LWD bulk density is used for $\rho_{\mathrm{b}}$. This estimate is subject to limitations because the LWD porosity is based on LWD values that average over a considerable vertical data sampling interval resolution $(15 \mathrm{~cm}$ for EcoScope measured density) [20]. When two or more lithofacies with different porosities interbed within the range of this resolution, the LWD derived in-situ porosity of reservoir formation might be over- or underestimated [13].

$n_{\mathrm{MAD}}$ is measured after the core sample has been uniaxially compressed and unloaded. No hydrate is present in this porosity measurement. This approach is described by [21]. It assumes that the sample is $100 \%$ water-saturated and is calculated as:

$$
n_{M A D}=\frac{m_{w} / \rho_{w}}{m_{w} / \rho_{w}+m_{g} / \rho_{g}}
$$

where $m_{\mathrm{w}}$ is the water mass between the measured dry mass and wet mass of the subsampled sediments. The grain density $\left(\rho_{\mathrm{g}}\right)$ is the same as used in Eq. 1 and the water density $\left(\rho_{\mathrm{w}}\right)$ is assumed to be $1.0 \mathrm{~g} / \mathrm{cm}^{3} . n_{\mathrm{Hg}}$ is the porosity from mercury porosimetry measurements. It is the volume of mercury intruded into the reconstituted sample at an intrusion pressure of $380 \mathrm{MPa}(55,000 \mathrm{psia})$ divided by the bulk volume of the sample. The bulk volume of the sample is determined from its dry mass using a measured grain density of $2.675 \mathrm{~g} / \mathrm{cm}^{3}$.

\subsection{Pressure core uniaxial consolidation}

The natural hydrate-bearing pressure core sample was consolidated in a pressurized permeameter test chamber within the hydrate stability zone $\left(P_{\mathrm{f}}=24.8 \mathrm{MPa}\right.$ and $T=$ $\left.6{ }^{\circ} \mathrm{C}\right)$. The test chamber, schematically shown with details in Figure 3, is capable of individually applying horizontal (or lateral) effective stress $\sigma_{h}{ }_{h}$ and vertical (or axial) effective stress $\sigma_{\mathrm{v}}^{\prime}$ to the core and performing a drained consolidation test. The horizontal stress is controlled with water pressure against the Viton membrane jacket. For hydrostatic or constant effective horizontal stress boundary conditions, the horizontal stress is positively controlled by an external pump. For uniaxial loading conditions, the confining fluid chamber is filled with water of a constant volume, and is assumed to prevent lateral expansion of the sample during axial loading. The horizontal stress is, therefore, equal to the water pressure and is passively monitored by a pressure sensor.

The vertical (axial) effective stress was incrementally applied to a target vertical effective stress (e.g., $1 \mathrm{MPa}, 2$ $\mathrm{MPa}, 3 \mathrm{MPa}$, and $3.8 \mathrm{MPa}$ ), using an external motorcontrolled actuator and was measured by the load cell. During consolidation to the target stress, drainage was allowed from both ends of the sample. When the consolidation approached steady-state (i.e., the sample was in a secondary consolidation state or no longer deforming), a further consolidation step was applied.

The vertical deformation of the core sample was measured from the displacement of the permeameter actuator with a resolution of $0.01 \mathrm{~mm}$. The accuracies of vertical (or axial) displacement, load cell force, pressure sensors were validated by compressing a standard-size steel sample (length $=80 \mathrm{~mm}$, diameter $=52 \mathrm{~mm}$ ) under known pump pressure. The steel was assumed incompressible under stress ranging from 0 to $10 \mathrm{MPa}$.

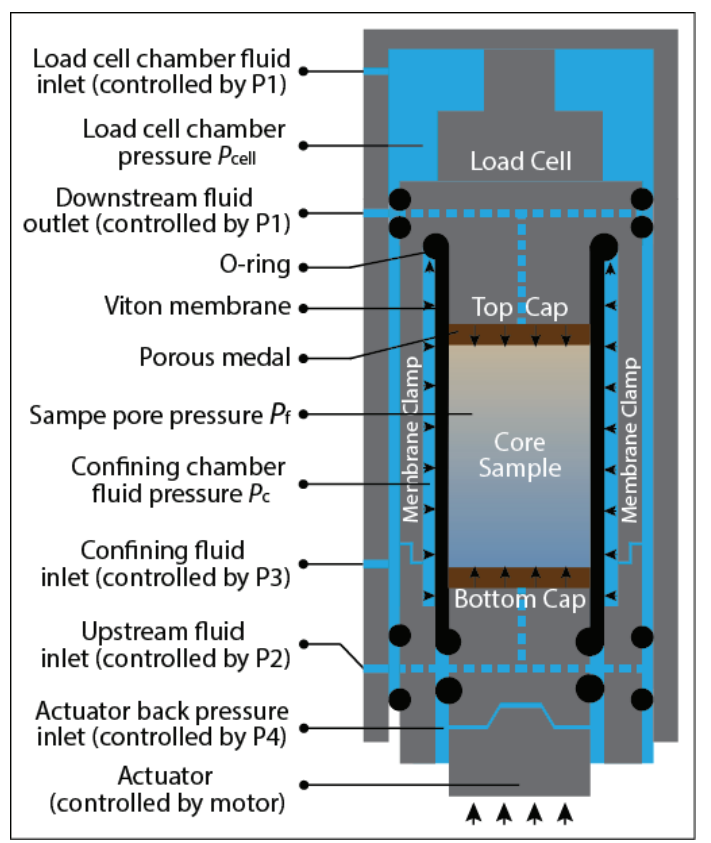

Fig.3. A schematic diagram of the permeameter test chamber. The pressure core sample (e.g., intact 4FB-8 in Fig. 1a or Fig.2b) can be uniaxially consolidated by constraining the fluid volume in the confining chamber. P1, P2, P3, and P4 refer to the hydraulic pump series.

\subsection{Constant-rate-of-strain consolidation}

We measured the compression behavior of a reconstituted sandy silt sample with uniaxial, constant-rate-of-strain (CRS), consolidation experiment. The test was performed at room temperature $\left(25^{\circ} \mathrm{C}\right)$ following ASTM Standards [22].

The specimen and its surrounding metal ring were loaded into the consolidation chamber with porous stones, and filter paper was placed on the top and base of the sample. The metal ring maintained uniaxial strain during consolidation. The consolidation chamber was sealed, filled with de-aired brine (3.5\% salinity), and pressurized with a constant pressure of $0.386 \mathrm{MPa}$ for at least 16 hours to ensure full saturation. Following this saturation stage, the drain valve at the base of the sample was locked, and the sample was consolidated vertically at a constant strain rate $(\varepsilon)$. A strain rate of $2.5 \% / \mathrm{hr}$ was applied.

The sandy silt lithofacies specimen was consolidated to a vertical effective stress of $12 \mathrm{MPa}$, then unloaded to 3.8 $\mathrm{MPa}$, then reloaded to $15 \mathrm{MPa}$ and finally unloaded to $0.05 \mathrm{MPa}$. The stress levels $12 \mathrm{MPa}$ and $15 \mathrm{MPa}$ were selected as two reference effective stresses (i.e., picked stress point for unloading). The stress $3.8 \mathrm{MPa}$ was the approximate representation of the in-situ vertical effective stress in the hydrate-bearing interval. The specimen was then unloaded to $0.1 \mathrm{MPa}$ under the same strain rate used for loading.

Axial load $\left(\sigma_{\mathrm{v}}\right)$ and specimen height $(H)$ were monitored throughout the test. Void ratio $(e)$ during the consolidation test was determined from strain data and the 
initial void ratio $\left(e_{0}\right)$. During virgin consolidation (the consolidation portion which occurs when the new effective stress is larger than its previously experienced maximum effective stress), the stress-strain relationship is defined by the compression index $C_{\mathrm{c}}$ :

$$
C_{c}=-\frac{e_{2}-e_{1}}{\log _{10}\left(\sigma_{v 2}^{\prime}\right)-\log _{10}\left(\sigma_{v 1}^{\prime}\right)}
$$

\subsection{Post-test characterization of pressure core}

After finishing the uniaxial consolidation test of hydratebearing sandy silt core, we dissociated the hydrate by depressurization and then took the hydrate-dissociated pressure core out of permeameter for a post-test characterization (Figure 4a to 4c). Smaller core plugs were subsampled from the dissociated pressure core sediment (Figure 4d to 4e). The subsampled core plugs were first oven-dried for 24 hours at $104{ }^{\circ} \mathrm{C}$ (Figure 4f) for the MAD porosity measurement, and the MICP measurements were then performed to characterize the pore throat size distribution and capillary behavior.

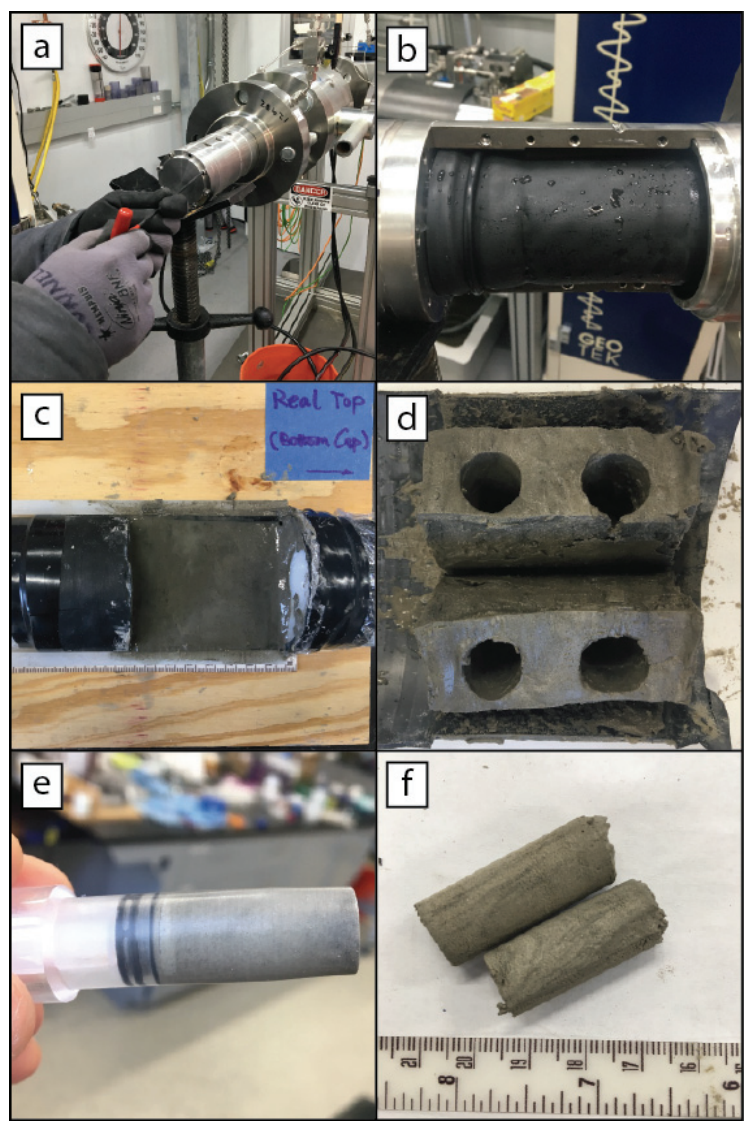

Fig.4. Subsampling procedure for the post-test characterization of the dissociated pressure core sample. (a) Dissembling the core chamber of the permeameter test section. (b) Dissociated pressure core sealed by the membrane. (c) Sliced dissociated pressure core with exposed cross-section surface. (d) Residual sediments after subsampling. (e) Subsampled core plug in the subsampling tool. (f) Oven-dried subsampled core plugs.

\section{Results and discussions}

\subsection{Pore size distribution}

The reconstituted sample and depressurized natural hydrate-bearing pressure core sample show almost identical pore throat size distributions (Figure 5). These measurements suggest that the reconstituted sample is a reliable physical representative of a depressurized natural pressure core sample in terms of the similarity in pore structures. Thus, the transport and mechanical properties estimated from the reconstituted samples provide important physical references to gain a better understanding of natural hydrate-bearing pressure cores.

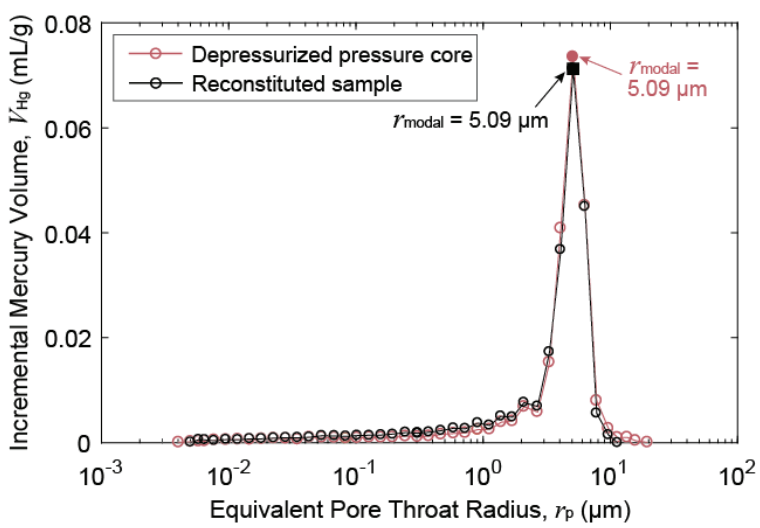

Fig.5. Incremental mercury injection volume with pore throat radius of depressurized pressure core (PC-4FB8) vs. reconstituted sample (R-4FB8).

\subsection{In-situ porosity}

The reconstituted sandy silt (black circles in Figure 6) has a low initial porosity of 0.43 at low effective stress $(0.01$ $\mathrm{MPa})$. The porosity slowly decreases with increasing stress. As the loading stress increased from 0 to the interpreted in-situ vertical effective stress of 3.8 MPa, the porosity $(n)$ of reconstituted sandy silt sample decreased to $0.38(e=0.61)$. This stress loading process is an analog to the stress that evolved during the burial of sediments (i.e., sedimentation) in the Gulf of Mexico. The porosity measured at in-situ stress matches the LWD porosity $(n=$ $\sim 0.38$ ), and the PCATS porosity $(n=\sim 0.38$ ) interpreted for hydrate-bearing sandy silt core sample (Table 1), confirming that the in-situ porosity of sediments is about 0.38 . The porosity measured from uniaxial consolidation of natural hydrate-bearing pressure core is in the range of 0.39 to 0.40 . After hydrate dissociation at the constant insitu effective stress, the porosity slightly dropped at a magnitude of one to two porosity units $(0.01$ to 0.02$)$. This dissociation induced porosity reduction behavior is also observed in [14].

This small porosity reduction can be explained via two mechanisms. First, as hydrate solid is totally removed from the porous medium, the stiffness of the core sample decreases. As a result, the porous material becomes more compliant. This stiffness-saturation correlation is speculated from the measurement that the body wave velocity of hydrate-bearing sediments increases with 
hydrate saturation [14]. Second, the hydrate in the pores of sediments may play a role in bearing a certain amount of effective stress. Once gas hydrate solid is dissociated, the total stress is redistributed to the solid grains of sediments, leading to a compaction of the core.

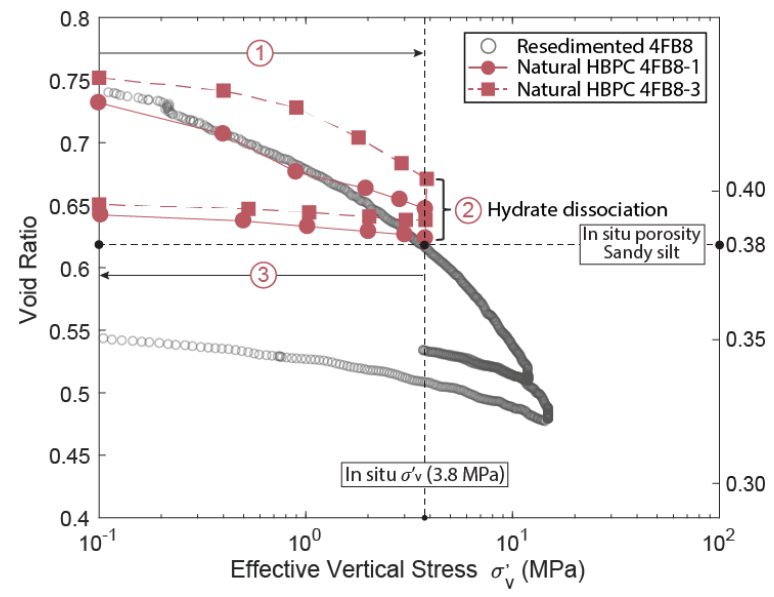

Fig.6. Evolution of void ratio with vertical effective stress during compression. Red squares and dots represent hydratebearing two pressure cores (4FB8-1 and 4FB8-3), showing there-stage compression behavior: (1) uniaxial loading with hydrate present; (2) hydrate dissociation at constant effective stress; (3) uniaxial unloading without hydrate. Black circles show the compression curve of reconstituted sandy silt (4FB-8).

\subsection{Compression behavior}

The difference in compression behaviors between hydrate-bearing pressure cores (PC-4FB8-1 and PC4FB8-3) and reconstituted hydrate-free sediments (R$4 \mathrm{FB} 8$ ) is small in the stress range of 0 to $3.8 \mathrm{MPa}$ (Figure $6)$. Both compression curves have a concave downward form with increasing effective stress, which is interpreted to be due to particle sliding, rolling at low stresses and grain-to-grain breakdown at high stresses [23]. The hydrate-bearing pressure cores are slightly stiffer than that of the reconstituted sample (Table 2) during the stress loading, which is possibly due to the hydrate in the cores.

The mechanical response (e.g., compaction) of naturally occurring methane hydrate in sediments to environmental changes (e.g., the effective stress change due to depressurization) is expected to be dependent on the distribution of the hydrate phase within the formation. The X-ray CT image (Figure 2a) of the pressure core indicates that the hydrate phase in GC 955 sandy silt is disseminated and nongrain-displacing. As limited by the CT image voxel resolution $(112 \mu \mathrm{m})$, it is indistinguishable whether the hydrate is pore-filling, frame-supporting, grain-coating, or contact cementing [24]. In addition, due to the complex dynamic evolution of gas migration, hydrate formation, and sedimentation, it is challenging and difficult to determine which hydrate morphology is influencing the mechanical behavior during the stress loading process.

Based on the similarity of the compression trending curves in Figure 6, it is only reasonable to rule out the possible hydrate phase as a contact-cementing in the formation. This is because that all of pore-filling, frame- supporting, grain-coating hydrate morphologies have little effect on bulk stiffness of hydrate-bearing sediments $[25,26]$.

Table 2. Compression properties of natural intact pressure core (PC-4FB8) and reconstituted sample (R-4FB8). Note: NC normal compression; UL - unloading; RC - recompression.

\begin{tabular}{|c|c|c|c|}
\hline Sample Name & R-4FB8 & PC-4FB8-1 & PC-4FB8-3 \\
\hline $\begin{array}{c}\text { Effective Stress } \\
\sigma^{\prime}{ }_{\mathrm{v}}(\mathrm{MPa}):\end{array}$ & $\begin{array}{c}\text { Compressi } \\
\text { on Index }\end{array}$ & $\begin{array}{c}\text { Compressio } \\
\text { n Index }\end{array}$ & $\begin{array}{c}\text { Compressio } \\
\text { n Index }\end{array}$ \\
\hline $0.1-1.0(\mathrm{NC})$ & $0.06\left(C_{\mathrm{c}}\right)$ & $0.06\left(C_{\mathrm{c}}\right)$ & $0.03\left(C_{\mathrm{c}}\right)$ \\
\hline $1.0-3.8(\mathrm{NC})$ & $0.11\left(C_{\mathrm{c}}\right)$ & $0.05\left(C_{\mathrm{c}}\right)$ & $0.09\left(C_{\mathrm{c}}\right)$ \\
\hline $3.8-1.0(\mathrm{UL})$ & $0.03\left(C_{\mathrm{s}}\right)$ & $0.02\left(C_{\mathrm{s}}\right)$ & $0.01\left(C_{\mathrm{s}}\right)$ \\
\hline $1.0-0.1(\mathrm{UL})$ & $0.02\left(C_{\mathrm{s}}\right)$ & $0.01\left(C_{\mathrm{s}}\right)$ & $0.01\left(C_{\mathrm{s}}\right)$ \\
\hline
\end{tabular}

\section{Concluding remarks}

Estimation of an accurate in-situ porosity and compression behavior of a hydrate-bearing reservoir is critical for providing a solid foundation for reservoir characterization. In this study, we carefully estimate the in-situ porosity and compressibility of a coarse-grained hydrate reservoir in GC 955 in the deepwater GOM by performing experiments both on hydrate-bearing sandy silt pressure cores and on same reservoir material that is reconstituted. Reconstituted samples and national intact hydrate-dissociated sediments are showing almost identical pore throat size distributions, suggesting the transport and mechanical properties estimated from the reconstituted samples are highly close to that of natural hydrate-bearing pressure cores.

The in-situ porosity $(n)$ of hydrate-saturated $\left(S_{\mathrm{h}}=\right.$ $83 \%$ ) sandy silt, as best-estimated from both LWD and calibrated PCATS densities, was found to be $\sim 0.38$ to 0.39 . The hydrate-bearing pressure core with the same hydrate saturation was uniaxially consolidated within the hydrate stability zone. We find that the best-estimated porosity of pressure core at the in-situ effective stress $\left(\sigma^{\prime}{ }_{\mathrm{v}}=3.8 \mathrm{MPa}\right)$ is $\sim 0.39$ to 0.40 , within one to two porosity units higher than that of its reconstituted material without hydrate $\left(S_{\mathrm{h}}\right.$ $=0, n=0.38$ ). Pressure core with $83 \%$ hydrate saturation has a compression index $\left(C_{\mathrm{c}}\right)$ of $\sim 0.05$ to 0.09 at $3.8 \mathrm{MPa}$, slightly stiffer than reconstituted sandy silts $\left(C_{\mathrm{c}}=0.11\right)$. This small difference of porosity and compression behavior between hydrate pressure core and reconstituted material implies that the hydrate, even at a high saturation in the pores of sediments, only has a weak influence on the bulk porosity and mechanical properties. We speculate that at $83 \%$ hydrate saturation, the hydrate morphology is in the form of either pore-filling, grain-coating, or framesupporting than contact-cementing. Identification of exact hydrate morphology in the pressure core requires further experimental efforts. Analysis of reconstituted sediments from hydrate-bearing pressure cores provides an intuitive and straightforward approach to understand some petrophysical components of the hydrate reservoir. This study will inform reservoir simulation models with fundamental geomechanical properties.

This work is the result of support provided by the U.S. Department of Energy under Contract No. DE-FE0023919. This support is gratefully acknowledged. 


\section{References}

1. Sloan, E.D. and C. Koh, Clathrate hydrates of natural gases. 2007: CRC press.

2. Collett, T.S., Energy Resource Potential of Natural Gas Hydrates. AAPG Bulletin, 2002. 86(11): p. 19711992.

3. Collett, T.S., M.W. Lee, W.F. Agena, J.J. Miller, K.A. Lewis, M.V. Zyrianova, R. Boswell, and T.L. Inks, Permafrost-associated natural gas hydrate occurrences on the Alaska North Slope. Marine and Petroleum Geology, 2011. 28(2): p. 279-294.

4. Boswell, R., D. Shelander, M. Lee, T. Latham, T. Collett, G. Guerin, G. Moridis, M. Reagan, and D. Goldberg, Occurrence of gas hydrate in Oligocene Frio sand: Alaminos Canyon Block 818: Northern Gulf of Mexico. Marine and Petroleum Geology, 2009. 26(8): p. 1499-1512.

5. Krey, V., J.G. Canadell, N. Nakicenovic, Y. Abe, H. Andruleit, D. Archer, A. Grubler, N.T.M. Hamilton, A. Johnson, V. Kostov, J.-F. Lamarque, N. Langhorne, E.G. Nisbet, B. O’Neill, K. Riahi, M. Riedel, W. Wang, and V. Yakushev, Gas hydrates: entrance to a methane age or climate threat? Environmental Research Letters, 2009. 4(3): p. 034007.

6. Ruppel, C.D. and J.D. Kessler, The interaction of climate change and methane hydrates. Reviews of Geophysics, 2017. 55(1): p. 126-168.

7. You, K. and P.B. Flemings, Methane Hydrate Formation in Thick Sandstones by Free Gas Flow. Journal of Geophysical Research: Solid Earth, 2018. 123(6): p. 4582-4600.

8. You, K., P.B. Flemings, A. Malinverno, T.S. Collett, and K. Darnell, Mechanisms of Methane Hydrate Formation in Geological Systems. Reviews of Geophysics, 2019. 57(4): p. 1146-1196.

9. Boswell, R., E. Myshakin, G. Moridis, Y. Konno, T.S. Collett, M. Reagan, T. Ajayi, and Y. Seol, India National Gas Hydrate Program Expedition 02 summary of scientific results: Numerical simulation of reservoir response to depressurization. Marine and Petroleum Geology, 2018.

10. Myshakin, E.M., Y. Seol, J.-S. Lin, S. Uchida, T.S. Collett, and R. Boswell, Numerical simulations of depressurization-induced gas production from an interbedded turbidite gas hydrate-bearing sedimentary section in the offshore India: Site NGHP02-16 (Area-B). Marine and Petroleum Geology, 2019. 108: p. 619-638.

11. Reece, J.S., P.B. Flemings, B. Dugan, H. Long, and J.T. Germaine, Permeability-porosity relationships of shallow mudstones in the Ursa Basin, northern deepwater Gulf of Mexico. Journal of Geophysical Research: Solid Earth, 2012. 117(B12).

12. Flemings, P.B. and D.M. Saffer, Pressure and Stress Prediction in the Nankai Accretionary Prism: A Critical State Soil Mechanics Porosity-Based Approach. Journal of Geophysical Research: Solid Earth, 2018. 123(2): p. 1089-1115.

13. Fang, Y., P.B. Flemings, H. Daigle, S.C. Phillips, K. Meazell, and K. You, Petrophysical Properties of the Green Canyon Block 955 Hydrate Reservoir Inferred from Reconstituted Sediments: Implications for Hydrate Formation and Production. AAPG Bulletin, 2020.

14. Yoneda, J., M. Oshima, M. Kida, A. Kato, Y. Konno, Y. Jin, and N. Tenma, Consolidation and hardening behavior of hydrate-bearing pressure-core sediments recovered from the Krishna-Godavari Basin, offshore India. Marine and Petroleum Geology, 2018.

15. Konno, Y., T. Fujii, A. Sato, K. Akamine, M. Naiki, Y. Masuda, K. Yamamoto, and J. Nagao, Key Findings of the World's First Offshore Methane Hydrate Production Test off the Coast of Japan: Toward Future Commercial Production. Energy \& Fuels, 2017. 31(3): p. 2607-2616.

16. Flemings, P.B., S.C. Phillips, R. Boswell, T.S. Collett, A.E. Cook, T. Dong, M. Frye, G. Guerin, D.S. Goldberg, M.E. Holland, J. Jang, K. Meazell, J. Morrison, J. O'Connell, T. Pettigrew, E. Petrou, P.J. Polito, A. Portnov, M. Santra, P.J. Schultheiss, Y. Seol, W. Shedd, E.A. Solomon, C. Thomas, W.F. Waite, and K. You, Pressure Coring a Gulf of Mexico Deepwater Turbidite Gas Hydrate Reservoir: Initial results from the UT-GOM2-1 Hydrate Pressure Coring Expedition. AAPG Bulletin, 2020.

17.Schultheiss, P., M. Holland, J. Roberts, Q. Huggett, M. Druce, and P. Fox. PCATS: pressure core analysis and transfer system. in Proceedings of the 7th International Conference on Gas Hydrates (ICGH 2011), Edinburgh, UK. 2011.

18. Germaine, J.T. and A.V. Germaine, Geotechnical laboratory measurements for engineers. 2009: John Wiley \& Sons.

19. Brooks, R.A. and G. Di Chiro, Beam hardening in $x$ ray reconstructive tomography. Physics in medicine \& biology, 1976. 21(3): p. 390.

20. Collett, T.S., M.W. Lee, M.V. Zyrianova, S.A. Mrozewski, G. Guerin, A.E. Cook, and D.S. Goldberg, Gulf of Mexico Gas Hydrate Joint Industry Project Leg II logging-while-drilling data acquisition and analysis. Marine and Pet. Geol., 2012. 34(1): p. 41-61.

21. Blum, P., Physical properties handbook: a guide to the shipboard measurement of physical properties of deep-sea cores. IODP, 1997.

22. ASTM D4186, Standard Test Method for OneDimensional Consolidation Properties of Saturated Cohesive Soils Using Controlled-Strain Loading. 2012, ASTM International: West Conshohocken, PA.

23. Pestana, J.M. and A.J. Whittle, Formulation of a unified constitutive model for clays and sands. International Journal for Numerical and Analytical Methods in Geomechanics, 1999. 23(12): p. 12151243.

24. Waite, W.F., W.J. Winters, and D.H. Mason, Methane hydrate formation in partially water-saturated Ottawa sand. Am. Mineralogist, 2004. 89(8-9): p. 1202-1207.

25. Madhusudhan, B.N., C.R.I. Clayton, and J.A. Priest, The Effects of Hydrate on the Strength and Stiffness of Some Sands. Journal of Geophysical Research: Solid Earth, 2019. 124(1): p. 65-75.

26. Clayton, C., J. Priest, and E. Rees, The effects of hydrate cement on the stiffness of some sands. Géotechnique, 2010. 60(6): p. 435-445. 